\title{
Mechanisms of nitrogen incorporation in GaAsN alloys
}

\author{
M. Reason, H. A. McKay, W. Ye, S. Hanson, and R. S. Goldman ${ }^{\text {a) }}$ \\ Department of Materials Science and Engineering, University of Michigan, Ann Arbor, \\ Michigan 48109-2136 \\ V. Rotberg \\ Department of Nuclear Engineering and Radiological Sciences, University of Michigan, Ann Arbor, \\ Michigan 48109-2145
}

(Received 8 April 2004; accepted 6 July 2004)

\begin{abstract}
We have investigated nitrogen incorporation mechanisms in dilute nitride GaAsN alloys grown by plasma-assisted molecular-beam epitaxy. A comparison of nuclear reaction analysis and Rutherford backscattering spectrometry in channeling and nonchanneling conditions reveals significant composition-dependent incorporation of $\mathrm{N}$ into nonsubstitutional sites, presumably as either $\mathrm{N}-\mathrm{N}$ or N-As split interstitials. Furthermore, we identify the $(2 \times 1)$ reconstruction as the surface structure which leads to the highest substitutional $\mathrm{N}$ incorporation, likely due to the high number of group V sites per unit area available for N-As surface exchange. (C) 2004 American Institute of Physics. [DOI: 10.1063/1.1789237]
\end{abstract}

For many III-V-N alloys, the band-gap energy is reduced as the nitrogen composition increases. ${ }^{1-3}$ For example, for $\sim 1 \% \mathrm{~N}$ added to GaAs, the band gap is reduced by $\sim 200 \mathrm{meV}$. $^{2}$ The resulting dilute nitride semiconductors are promising for a wide range of applications including longwavelength light-emitters, high-performance electronic devices, and high efficiency solar cells. For GaAsN alloys, the electron mobility and optical emission intensity decrease as the nitrogen incorporation increases. ${ }^{4-6}$ However, conflicting results have been reported regarding the mechanism of $\mathrm{N}$ incorporation in $\mathrm{GaAsN}^{7-11}$ and the relationship between the mechanism of $\mathrm{N}$ incorporation and the GaAsN surface reconstruction has not been reported.

Ahlgren et $\mathrm{l}^{7}{ }^{7}$ observed a nearly constant interstitial $\mathrm{N}$ concentration of $2 \times 10^{19} \mathrm{~cm}^{-3}$ for $100 \mathrm{~nm}$ thick films with total $\mathrm{N}$ concentrations ranging from 1.8 to $9.7 \times 10^{20} \mathrm{~cm}^{-3}$. Bisognin et al. ${ }^{8}$ reported $\mathrm{N}$ contamination of $2 \times 10^{14} \mathrm{~cm}^{-2}$ on the surface of a series of $150 \mathrm{~nm}$ thick GaAsN films with total $\mathrm{N}$ concentrations ranging from 3.8 to $10 \times 10^{20} \mathrm{~cm}^{-3}$. They reasoned that the apparent interstitial $\mathrm{N}$ measured by Ahlgren $e t$ al. was likely caused by a similar $\mathrm{N}$ surface contamination, which would be consistent with the firstprinciples total-energy calculations prediction of an interstitial $\mathrm{N}$ concentration of $\sim 1 \times 10^{14} \mathrm{~cm}^{-3}$. ${ }^{9}$ On the other hand, Spruytte et al. ${ }^{10}$ reported a much larger interstitial N concentration of $1.5 \times 10^{20} \mathrm{~cm}^{-3}$ for one $200 \mathrm{~nm}$ sample with total $\mathrm{N}$ concentration of $7 \times 10^{20} \mathrm{~cm}^{-3}$, likely not entirely accounted for by $\mathrm{N}$ surface contamination. The potential artifact of $\mathrm{N}$ surface contamination may be further minimized for even thicker films. To date, Alt et al. ${ }^{11}$ have reported an interstitial concentration of $\sim 6 \times 10^{18} \mathrm{~cm}^{-3}$ in one $350 \mathrm{~nm}$ thick GaAsN film with total $\mathrm{N}$ concentration of 1.3 $\times 10^{20} \mathrm{~cm}^{-3}$. We report significant composition-dependent interstitial $\mathrm{N}$ incorporation in $500 \mathrm{~nm}$ thick GaAsN films with total $\mathrm{N}$ concentration ranging from 1.5 to 8.5 $\times 10^{20} \mathrm{~cm}^{-3}$. We identify the $(2 \times 1)$ reconstruction as the surface structure which leads to the highest substitutional $\mathrm{N}$

\footnotetext{
a) Author to whom correspondence should be addressed; electronic mail: rsgold@umich.edu
}

incorporation, likely due to the high number of group $\mathrm{V}$ sites per unit area available for $\mathrm{N}-\mathrm{As}$ exchange.

The $\mathrm{GaAs}_{1-x} \mathrm{~N}_{x}$ alloy films were grown on epiready (001) GaAs by molecular-beam epitaxy (MBE), using solid $\mathrm{Ga}$ and $\mathrm{As}_{4}$ or $\mathrm{As}_{2}$, and a radio frequency (rf) plasma source, with ultrahigh purity $10 \% \mathrm{~N}_{2} / \mathrm{Ar}$. The $\mathrm{N}$ composition in the $\mathrm{GaAs}_{1-x} \mathrm{~N}_{x}$ layers, $x$, was adjusted by varying the GaAs growth rate between 0.25 and $1.2 \mu \mathrm{m} / \mathrm{h} .{ }^{10}$ The surface reconstruction was monitored in situ with reflection highenergy electron diffraction (RHEED). The substrate temperature was monitored using an optical pyrometer, calibrated to the $(2 \times 4)-(3 \times 1)$ and $(3 \times 1)-(4 \times 2)$ surface reconstruction changes at 500 and $595^{\circ} \mathrm{C}$, respectively. ${ }^{12}$

GaAs substrates were mounted either on In-bonded or In-free molybdenum blocks. Each sample contained an initial $500 \mathrm{~nm}$ GaAs buffer layer grown at $580^{\circ} \mathrm{C}$. For some samples, the substrate temperature was lowered to $500^{\circ} \mathrm{C}$, and an additional $20 \mathrm{~nm}$ layer of GaAs was grown. ${ }^{13}$ For other samples, a series of annealing steps was performed at 580 and $530^{\circ} \mathrm{C}$ with As overpressure, followed by a $370^{\circ} \mathrm{C}$ anneal without As. ${ }^{14}$ Finally, $\sim 500 \mathrm{~nm}$ thick $\mathrm{GaAs}_{1-x} \mathrm{~N}_{x}$ layers with $x$ ranging from 0.005 to 0.035 were grown at 400 , 550 , or $580^{\circ} \mathrm{C}$. All the $\mathrm{GaAs}_{1-x} \mathrm{~N}_{x}$ layers were grown with a high As/Ga beam-equivalent pressure ratio $\left(>30\right.$ for $\mathrm{As}_{4}$ and $\sim 20$ for $\mathrm{As}_{2}$ ). Some of the samples were subsequently annealed at the GaAsN growth temperature with As overpressure, followed by a $370^{\circ} \mathrm{C}$ anneal without As.

Figure 1 shows the RHEED patterns collected during the growth of the $580^{\circ} \mathrm{C}$ GaAs buffer layer, and the GaAsN layers at 400,550 , and $580^{\circ} \mathrm{C}$. During the growth of the $580^{\circ} \mathrm{C}$ buffer layer, RHEED reveals a streaky $(2 \times 4)$ pattern, shown in Figs. 1(a) and 1(b). For the GaAsN layers grown at $400^{\circ} \mathrm{C}$, the intensity of the center streak of the $(2 \times)$ pattern is reduced, and a streaky $(2 \times 1)$ pattern is evident, as shown in Figs. 1(c) and 1(d). For GaAsN layers grown at $550^{\circ} \mathrm{C}$, the center streak of the $(2 \times)$ pattern transforms to two streaks, and a slightly spotty $(3 \times 1)$ pattern is evident, as shown in Figs. 1(e) and 1(f). Finally, for GaAsN layers grown at $580^{\circ} \mathrm{C}$, the RHEED pattern is essentially identical to that shown for the GaAs buffer layer in Figs. 1(a) 
[110]
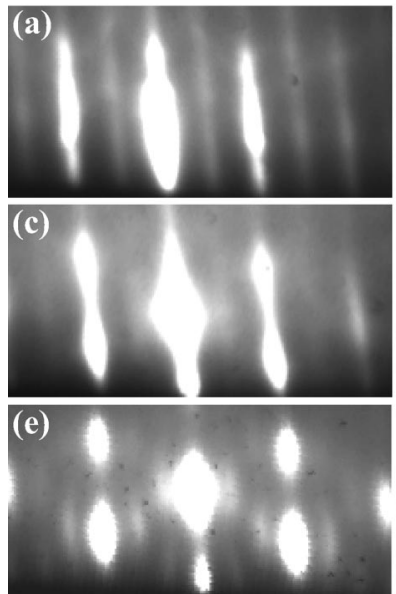

[110]

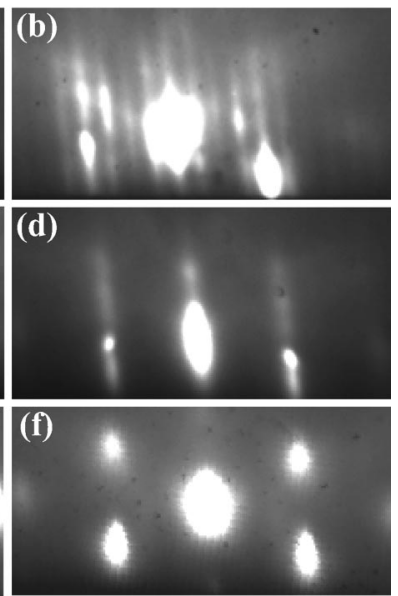

FIG. 1. RHEED patterns collected along the [110] and [1 $1 \overline{1} 0]$ axes during growth of (a) and (b) GaAs buffer layer grown at $580^{\circ} \mathrm{C}$, and $\mathrm{GaAsN}$ films at (c) $400^{\circ} \mathrm{C}$, (d) $400^{\circ} \mathrm{C}$, (e) $550^{\circ} \mathrm{C}$, and (f) $550^{\circ} \mathrm{C}$. GaAsN grown at $580^{\circ} \mathrm{C}$ was essentially identical to (a) and (b).

and 1(b). These surface reconstructions are consistent with reports of GaAsN growth. ${ }^{15-17}$ The surface morphology of the films was examined ex situ with tapping mode atomic force microscopy (AFM). For GaAsN films grown at $400^{\circ} \mathrm{C}$, the rms roughness was $0.3 \pm 0.1 \mathrm{~nm}$, similar to that of the GaAs buffer layer. Meanwhile, for GaAsN films grown in the range of $550-580^{\circ} \mathrm{C}$, the rms roughness increased to $1.3 \pm 0.1 \mathrm{~nm}$.

The total $\mathrm{N}$ concentration and fraction of $\mathrm{N}$ incorporated substitutionally, $f$, were determined using nuclear reaction analysis (NRA) with the ${ }^{14} \mathrm{~N}\left(d, \alpha_{0}\right){ }^{12} \mathrm{C}$ and ${ }^{14} \mathrm{~N}\left(d, \alpha_{1}\right){ }^{12} \mathrm{C}$ reactions. We used $1.4 \mathrm{MeV}$ deuterons, which have a penetration depth of $\sim 15 \mu \mathrm{m}$, much greater than the thickness of the GaAsN films. ${ }^{18}$ The emitted $\alpha_{0}$ and $\alpha_{1}$ particles were collected using a detector with a solid angle of $5 \mathrm{msr}$, at a scattering angle of $150^{\circ}$, for which the scattering cross section is well known. ${ }^{19}$ The $\mathrm{N}$ concentrations determined using the yields from $\alpha_{0}$ and $\alpha_{1}$ particles were within $6 \%$, less than the average measurement error. NRA measurements of GaAsN and Rutherford backscattering spectrometry (RBS) measurements of GaAs were performed in both [001] channeling conditions, and tilted $\sim 5^{\circ}$ away from the [001] axis, which we define as a "nonchanneling" condition. Multiple channeling and nonchanneling measurements performed on the same location revealed negligible lattice damage induced by the deuteron beam. To determine $f$, we assume stoichiometric undoped GaAs reference samples with negligible interstitial concentrations, typical of high temperature grown GaAs. ${ }^{20}$ Furthermore, we assume homogeneous random GaAsN alloys, as suggested by prior scanning tunneling microscopy measurements of similar samples. ${ }^{21}$ The fraction of $\mathrm{N}$ incorporating substitutionally is given by

$$
f=\frac{1-\chi(\mathrm{N})}{1-\chi_{\min }(\mathrm{GaAs})},
$$

where $\chi_{\min }(\mathrm{GaAs})[\chi(\mathrm{N})]$ is the ratio of the yield in channeling and nonchanneling conditions for GaAs $[\mathrm{N}]$. For GaAs reference samples grown by $\mathrm{MBE}, \chi_{\min }$ was $0.057 \pm 0.005$, similar to earlier reports. ${ }^{7}$ The $\chi(\mathrm{N})$ values ranged from $0.14 \pm 0.03$ to $0.52 \pm 0.05$ for a variety of GaAsN films.

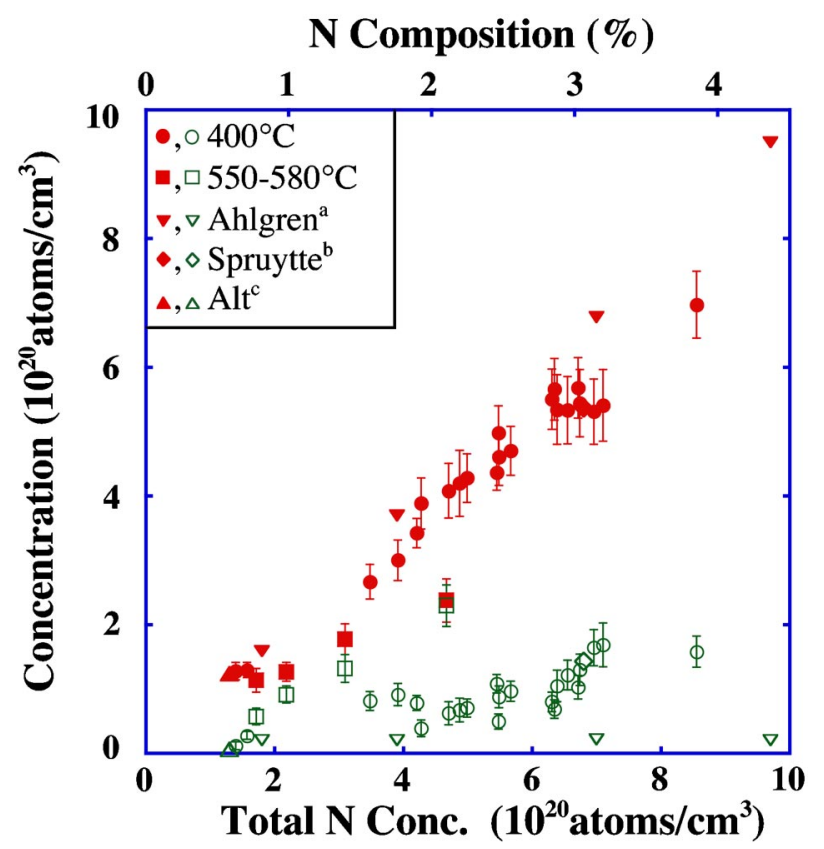

FIG. 2. (Color online) Substitutional (solid symbols) and interstitial (open symbols) concentrations vs. total $\mathrm{N}$ concentration for $\mathrm{GaAs}_{1-x} \mathrm{~N}_{x}$ films with varying $x$. The concentration of interstitial $\mathrm{N}$ increases with total $\mathrm{N}$ concentation. ${ }^{\mathrm{a}}$ See Ref. 7. ${ }^{\mathrm{b}}$ See Ref. 10. ${ }^{\mathrm{c}}$ See Ref. 11.

Figure 2 shows a plot of substitutional and interstitial $\mathrm{N}$ concentrations as a function of the total $\mathrm{N}$ concentration for a variety of films. The plot reveals an increase in both substitutional and interstitial $\mathrm{N}$ concentrations as a function of total $\mathrm{N}$ concentration. For total $\mathrm{N}$ concentrations below 2 $\times 10^{20} \mathrm{~cm}^{-3}$, we observe interstitial concentrations similar to Ahlgren $e t$ al. ${ }^{7}$ and Alt et al. ${ }^{11}$ However, for total $\mathrm{N}$ concentrations above $4 \times 10^{20} \mathrm{~cm}^{-3}$, we observe significantly greater interstitial concentrations than Ahlgren et $_{\text {al. }}{ }^{7}$ Instead, we observe interstitial N concentrations similar to Spruytte $e t$ $a l .{ }^{10}$ Since our films are $500 \mathrm{~nm}$ thick, N surface contamination of $2 \times 10^{14} \mathrm{~cm}^{-2}$ would lead to $4 \times 10^{18} \mathrm{~cm}^{-3}$ interstitial $\mathrm{N}$ concentration, less than $33 \%$ of our lowest interstitial $\mathrm{N}$ concentration. Thus, we expect that our significant interstitial $\mathrm{N}$ concentrations cannot be accounted for by $\mathrm{N}$ surface contamination. Interestingly, for GaAsN grown at 550 and $580^{\circ} \mathrm{C}$, with the $(3 \times 1)$ and $(2 \times 4)$ reconstructions, respectively, we observe substantially higher fractions of interstitial $\mathrm{N}$ than for GaAsN grown at $400^{\circ} \mathrm{C}$, with the $(2 \times 1)$ reconstruction. Since the $(2 \times 1)$ reconstructed surface has significantly more group $\mathrm{V}$ sites per unit area than the $(3 \times 1)$ or $(2 \times 4)$ surfaces, ${ }^{22-24} \mathrm{~N}$ atoms may more effectively incorporate substitutionally via $\mathrm{N}-\mathrm{As}$ exchange. ${ }^{25}$ This change in the mechanism of $\mathrm{N}$ incorporation for high temperature GaAsN growth may contribute to the increase in surface roughness discussed earlier. A similar trend has been reported for nonsubstitutional $\mathrm{C}$ incorporation in $\mathrm{SiGeC}$ alloys. ${ }^{26}$

The interstitial concentrations shown in Fig. 2 indicate the number of $\mathrm{N}$ atoms in interstitial sites per unit volume, which may not be equivalent to the number of $\mathrm{N}$ interstitial defects per unit volume. Both calculations ${ }^{9}$ and experiments ${ }^{27}$ have suggested that the dominant form of interstitial $\mathrm{N}$ is either the $\mathrm{N}-\mathrm{As}$ split interstitial, $\mathrm{NAs}_{\text {split, }}$ or the $\mathrm{N}-\mathrm{N}$ split interstitial, $\mathrm{NN}_{\text {split }}$, shown in Fig. 3. Our channeling measurements do not distinguish these forms of inter- 


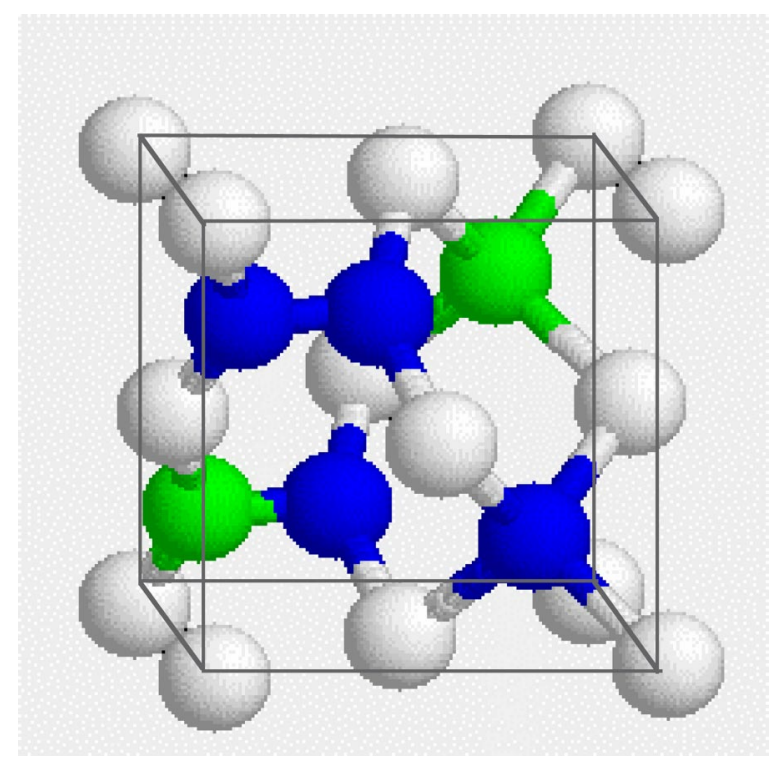

FIG. 3. (Color online) Ball and stick crystal schematic for GaAsN with substitutional $\mathrm{N}, \mathrm{N}-\mathrm{As}$ split interstitial, and $\mathrm{N}-\mathrm{N}$ split interstitial. The white, grey (green), and black (blue) spheres represent $\mathrm{Ga}, \mathrm{As}$, and $\mathrm{N}$, respectively.

stitial $\mathrm{N}$. If $\mathrm{NAs}_{\text {split }}$ is dominant in GaAsN, the interstitial concentration would be equal to the concentration of $\mathrm{N}$ atoms in interstitial sites in Fig. 2. Alternatively, if $\mathrm{NN}_{\text {split }}$ is dominant in GaAsN, the interstitial concentration would be equal to half the concentration of $\mathrm{N}$ atoms in interstitial sites in Fig. 2. Deep level transient Fourier spectroscopy (DLTFS) measurements have suggested that $\mathrm{NN}_{\text {split }}$ and $\mathrm{NAs}_{\text {split }}$ are the dominant defects for $\mathrm{GaAs}_{1-x} \mathrm{~N}_{x}$ with $x<0.1 \%$ and $x$ $=0.5 \%$, respectively. ${ }^{27}$ In order to determine the dominant defect for higher $\mathrm{N}$ compositions, further DLTFS experiments are needed.

In summary, we have investigated nitrogen incorporation mechanisms in $\mathrm{GaAs}_{1-x} \mathrm{~N}_{x}$ films using a combination of in situ RHEED and ex situ AFM, NRA, and RBS. A comparison of NRA and RBS in channeling and nonchanneling conditions reveals significant composition-dependent nonsubstitutional $\mathrm{N}$, which cannot be accounted for by $\mathrm{N}$ surface contamination. Furthermore, growth of GaAsN films at $400^{\circ} \mathrm{C}$, with a $(2 \times 1)$ surface reconstruction, leads to the highest substitutional incorporation of $\mathrm{N}$. This is likely due to the higher number of group $\mathrm{V}$ sites per unit area available on the $(2 \times 1)$ reconstructed surface in comparison with the $(3 \times 1)$ and $(2 \times 4)$ reconstructed surfaces.

This work was supported in part by the National Science Foundation Early Faculty CAREER, Instrumentation for Materials Research, and Nanoscale Exploratory Research Pro- grams (Grant Nos. 9773707, 9975701, and 0210714); the DoD Multidisciplinary University Research Initiative administered by the Air Force Office of Scientific Research under Grant No. F49620-00-1-0328; the Department of Energy, through the National Renewable Energy Laboratory Photovoltaics Beyond the Horizon Program under Contract No. ACQ-1-30619-14; the TRW Foundation; and k-Space Associates, Inc. The authors acknowledge G.S. Was, S.-H. Wei, and A. Zunger for useful discussions, and the assistance of the staff of the Michigan Ion Beam Laboratory.

${ }^{1}$ M. Weyers, M. Sato, and H. Ando, Jpn. J. Appl. Phys., Part 1 31, 853 (1992).

${ }^{2}$ W. G. Bi and C. W. Tu, Appl. Phys. Lett. 70, 1608 (1997).

${ }^{3}$ L. Bellaiche, S.-H. Wei, and A. Zunger, Phys. Rev. B 54, 17568 (1996).

${ }^{4}$ R. Mouillet, L.-A. de Vaulchier, E. Deleporte, Y. Guldner, L. Travers, and J.-C. Harmand, Solid State Commun. 126, 333 (2003).

${ }^{5}$ J. S. Wang, A. R. Kovsh, L. Wei, J. Y. Chi, Y. T. Wu, P. Y. Wang, and V. M. Ustinov, Nanotechnology 12, 430 (2001).

${ }^{6}$ I. A. Buyanova, W. M. Chen, and C. W. Tu, Semicond. Sci. Technol. 17, 815 (2002).

${ }^{7}$ T. Ahlgren, E. Vainonen-Ahlgren, J. Likonen, W. Li, and M. Pessa, Appl. Phys. Lett. 80, 2314 (2002).

${ }^{8}$ G. Bisognin, D. De Salvador, C. Mattevi, M. Berti, A. V. Drigo, G. Ciatto, L. Grenouillet, P. Duvaut, P. Gilet, and H. Mariette, J. Appl. Phys. 95, 48 (2004).

${ }^{9}$ S. B. Zhang and S.-H. Wei, Phys. Rev. Lett. 86, 1789 (2001).

${ }^{10}$ S. G. Spruytte, M. C. Larson, W. Wampler, C. W. Coldren, H. E. Petersen, and J. S. Harris, J. Cryst. Growth 227-228, 506 (2001).

${ }^{11}$ H. C. Alt, A. Y. Egorov, H. Riechert, J. D. Meyer, and B. Wiedemann, Physica B 308-310, 877 (2001).

${ }^{12} \mathrm{H}$. Shtrikman (private communication).

${ }^{13}$ D. W. Gotthold, S. Govindaraju, T. Mattord, A. L. Holmes, Jr., and B. G. Streetman, J. Vac. Sci. Technol. A 18, 461 (2000).

${ }^{14}$ B. D. Schultz, H. H. Farrell, M. M. R. Evans, K. Ludge, and C. J. Palmstrom, J. Vac. Sci. Technol. B 20, 1600 (2002).

${ }^{15}$ M.-A. Pinault and E. Tournie, Appl. Phys. Lett. 79, 3404 (2001).

${ }^{16}$ A. R. Kovsh, J. S. Wang, L. Wei, R. S. Shiao, J. Y. Chi, B. V. Volovik, A. F. Tsatsul'nikov, and V. M. Ustinov, J. Vac. Sci. Technol. B 20, 1158 (2002).

${ }^{17}$ S. Z. Wang, S. F. Yoon, and W. K. Loke, J. Appl. Phys. 94, 2662 (2003).

${ }^{18}$ TRIM code, available at www.srim.org.

${ }^{19}$ G. Amsel, J. P. Nadai, E. d'Artemare, D. David, E. Girard, and J. Moulin, Nucl. Instrum. Methods 92, 481 (1971).

${ }^{20}$ R. A. Stall, C. E. C. Wood, P. D. Kirchner, and L. F. Eastman, Electron. Lett. 16, 171 (1980).

${ }^{21}$ H. A. McKay, R. M. Feenstra, T. Schmidtling, and U. W. Pohl, Appl. Phys. Lett. 78, 82 (2001).

${ }^{22}$ Y.-C. Chang and D. E. Aspnes, Phys. Rev. B 41, 12002 (1990).

${ }^{23}$ H. H. Farrell, M. C. Tamargo, J. L. de Miguel, F. S. Turco, D. M. Hwang, and R. E. Nahory, J. Appl. Phys. 69, 7021 (1991).

${ }^{24}$ W. G. Schmidt, Appl. Phys. A: Mater. Sci. Process. 75, 89 (2002).

${ }^{25}$ R. J. Hauenstein, D. A. Collins, X. P. Cai, M. L. O'Steen, and T. C. McGill, Appl. Phys. Lett. 66, 2861 (1995).

${ }^{26}$ C. Calmes, D. Bouchier, D. Debarre, V. Le Thanh, and C. Clerc, Thin Solid Films 428, 150 (2003).

${ }^{27}$ P. Krispin, V. Gambin, J. S. Harris, and K. H. Ploog, J. Appl. Phys. 93, 6095 (2003). 